\title{
MANAGEMENT OF A OBESE PATIENT WITH CERVICAL FRACTURE AND POLYTRAUMA WITH BILATERAL ULTRASOUND GUIDED UPPER LIMB BLOCK FOR REPAIR OF FRACTUREBOTH UPPERLIMBS
}

\author{
Usha Kumari Chaudhary ${ }^{1}$, Sudershan Chaudhary², Vishal Devra ${ }^{3}$, Arvind Kumar ${ }^{4}$, Shelly Rana ${ }^{5}$
}

\section{HOW TO CITE THIS ARTICLE:}

Usha Kumari Chaudhary, Sudershan Chaudhary, Vishal Devra, Arvind Kumar, Shelly Rana. "Management of a Obese Patient with Cervical Fracture and Polytrauma with Bilateral Ultrasound Guided Upper Limb Block for Repair of Fracture both Upper Limbs". Journal of Evolution of Medical and Dental Sciences 2015; Vol. 4, Issue 52, June 29; Page: 9112-9115, DOI: 10.14260/jemds/2015/1321

ABSTRACT: Difficult airway and difficult intravenous access are known complications associated with obesity. A fifty two years female (BMI- $38.9 \mathrm{~kg} / \mathrm{m}^{2}$ ) presented with polytrauma with fracture mid shaft left humerus, fracture right radius and ulna onx ray. CT Scan showed fracture lateral mass of $\mathrm{C}_{1}$ vertebrae, burst fracture $\mathrm{T}_{2}$, spinous process of $\mathrm{C}_{7}$ and $\mathrm{T}_{1}$, fracture left clavicle and multiple fractures of first and second rib posteriorly. The ultrasound proved beneficial for cannulating the right infraclavicular subclavianvein. Ultrasound was also used for providing peripheral nerve block for providing anaesthesia for surgery on both upper limbs. The patient was given ultrasound guided axillary brachial plexus block on the right side and interscalene brachial plexus block on left side. The surgery was performed successfully under the blocks and was uneventful.

KEYWORDS: Obese, Ultrasound guided, Axillary brachial plexus block, Interscalene brachial plexus block.

INTRODUCTION: General anaesthesia is associated with increased mortality and morbidity in the obese patients. Similarly the regional anaesthesia in the obese can be technically challenging because of difficulties in identifying the usual bony land marks. A fifty two years obese patient reported to us in operation theatre with the multiple fractures for repair of fractures both upper limbs. The ultrasound guided brachial blocks were a preferred techniques for the surgery. Use of ultrasound has revived these peripheral nerve blocks as the visual guidance provided by the ultrasound not only results in the successful blocks but also avoids the complications associated with the blind procedures.

The written informed consent has been obtained from the patient for the publication of the case report.

CASE DESCRIPTION: A fifty two years female with history of RSA presented to anaesthesia department for repair of open fracture both bones forearm right and fracture humerus left for open reduction and internal fixation.

Patient presented with history of car accident while travelling. There was injury toback, both upper limbs, right lower limb, left clavicle and left first and second rib. No history of unconsciousness, vomiting, seizures or ENT bleed. Patient was a known case of hypertension, taking Tab. Amlodipine $5 \mathrm{mg}$ orally and Tab. Ecosprin $75 \mathrm{mg}$ orally once daily. No history of any cardiac event in the past. No history of any other co-morbid conditions.

On general physical examination, Patient was conscious, cooperative, well oriented to time, place and person. GCS was 15/15. Patient was obese with height of $159.5 \mathrm{~cm}$, weight- $98 \mathrm{~kg}$ and BMI$38.9 \mathrm{~kg} / \mathrm{m}^{2}$ Patient was pale, NIBP - 160/90 mm Hg, PR $-99 / \mathrm{min}$. There was no visible IV access in 
lower limbs except for 20G cannula in situ in left lower limb. Other systems were normal. Airway examination showed inter incisor distance of $3.5 \mathrm{~cm}$. Patient was wearing the cervical collar to avoid neck movement. Modified Mallampati grade, neck flexion and neck extension could not be assessed because of the injury to cervical spine. Mentohyoid distance, and Thyromental Distance could not be assessed. Neck circumference was 18 inches.

\section{Investigations:}

Hb. 8.1gm\% TLC 12, 400/ $\mathrm{mm}^{3}$, Platelet count- $1.24 \mathrm{lac} / \mathrm{mm}^{3}$ coagulation profile was normal, S. Na+ /S.K+142/ 3.7, S.Urea /S.Creatinine 22/0.79 ECG - normal:

CT cervical spine and thorax (Figure 1):

Fracture lateral mass of $\mathrm{C}_{1}$ vertebrae superiorly lateral side. There was burst fracture $\mathrm{T}_{2}$, fracture spinous process of $\mathrm{C}_{7}$ and $\mathrm{T}_{1}$, fracture left clavicle and multiple fractures of first and second rib posteriorly. No evidence of bony cervical canal stenosis.

CT Head appeared normal.

X-Ray Right upper limb showed fracture radius and ulna (Figure 2).X-Ray left upper limb showed fracture mid shaft humerus (Figure3).

$\mathrm{X}$-Ray right lower limb showed closed fracture both bones.

Patient was posted for open reduction and internal fixation of both the upper limb fractures. As the fibero-optic was not available the patient was planned for surgery under peripheral nerve block keeping the difficult airway cart ready. The difficult airway cart contained assorted sizes of blades, assorted sizes of endotracheal tubes, McCoy laryngoscpe, elastic gum bougie, LMA size 3 and 4 besides the normal airway cart. The patient was planned for intubation with MILS (Manual In Line Stabilisation) in case of failure of block.

After attaching the basic monitors, the right subclavian vein cannulated using infraclavicular route under ultrasound guidance with a linear probe of 9-12 $\mathrm{Hz}$ of Micromaxxsonosite ultrasound machine. The right upper limbanaesthetized using ultrasound guided axillary brachial plexus block using $22 \mathrm{G}$ cannula using a linear probe of $9-12 \mathrm{~Hz}$ of Micromaxxsonosite ultrasound machine. Under ultrasound guidance $25 \mathrm{ml}$ of drug was given -10 ml of ligno+adr $(1: 200,000)$ and $15 \mathrm{ml}$ of $0.25 \%$ bupivacaine. Adequate analgesia and anaesthesia achieved for the surgery.

The duration of surgery was 2.5 hours. At the end of surgery when the surgeon started applying sutures, the interscalene brachial plexus block was given on the left side using ultrasound.Total $25 \mathrm{ml}$ of drug- $15 \mathrm{ml}$ of ligno+adr (1: 200,000) and $10 \mathrm{ml}$ of bupivacaine $0.25 \%$ was injected around the nerve bundles. Adequate motor and sensory blockade was achieved. The surgery was successfully completed using the block. Hence ultrasound has played a very important role in the management of a case of polytrauma with predicted difficult airway with fracture ribs and cervical fracture.

DISCUSSION: The use of ultrasound to perform peripheral nerve block is a relatively new technique that is rapidly gaining popularity over more traditional techniques of peripheralnerve stimulators and paresthesia. ${ }^{1}$ The use of ultrasound for regional anaesthesia was first reported by La Grange et al in 1978, who performed supraclavicular brachial plexus blocks with a doppler ultrasound blood flow detector. $^{2}$

In recent years, real time ultrasonographic guidance has been introduced for peripheral nerve blocks which is rapidly evolving and becoming increasingly more useful field of regional anaesthesia. 
It has also resulted in rejuvenation of unpopular blocks like interscalene and axillarybrachial plexus block due to ability to visualize plexus, artery, first rib and pleura. ${ }^{1}$

In a similar case, Van Geffen et al. ${ }^{3}$ performed interscalene block in a 7-yrs-old child with femur fibula ulna syndrome (presenting with hypoplasia of the humerus) highlighting that ultrasound can be an important modality in those patients in whom the use of other techniques is impossible.

In this case the patient had presented with fracture lateral mass of first cervical spine and multiple fractures first and second ribs. The patient had no neurological deficit, but we prefered to avoid general anaesthesia because of the fracture cervical spine and due toother complications associated with general anaesthesia e.g. obesity, difficult intubation and fractured ribs. Also by using axillary approach on one side and interscalene approach on the other side we have avoided the complications associated with the paralysis of bilateral phrenic nerve.

\section{REFERENCES:}

1. Rupera KB, Khara BN, Shah VR, Parikh BK. Supra-clavicular brachial plexus block: ultrasonography guided technique offer advantage over peripheral nerve stimulator guided technique. National journal of medical research 2013; vol. 3: 3: 241-4.

2. La Grange P, Foster P, Pretorius L. Application of the Doppler ultrasound blood flowdetector in supraclavicular brachial plexus block. BJA 1978; 50: 965-7.

3. Van Geffen GJ, Tielens L, Gielen M: Ultrasound-guided interscalene brachial plexus block in a child with femur fibula ulna syndrome. Pediatr Anesth 2006; 16: 330 -2.

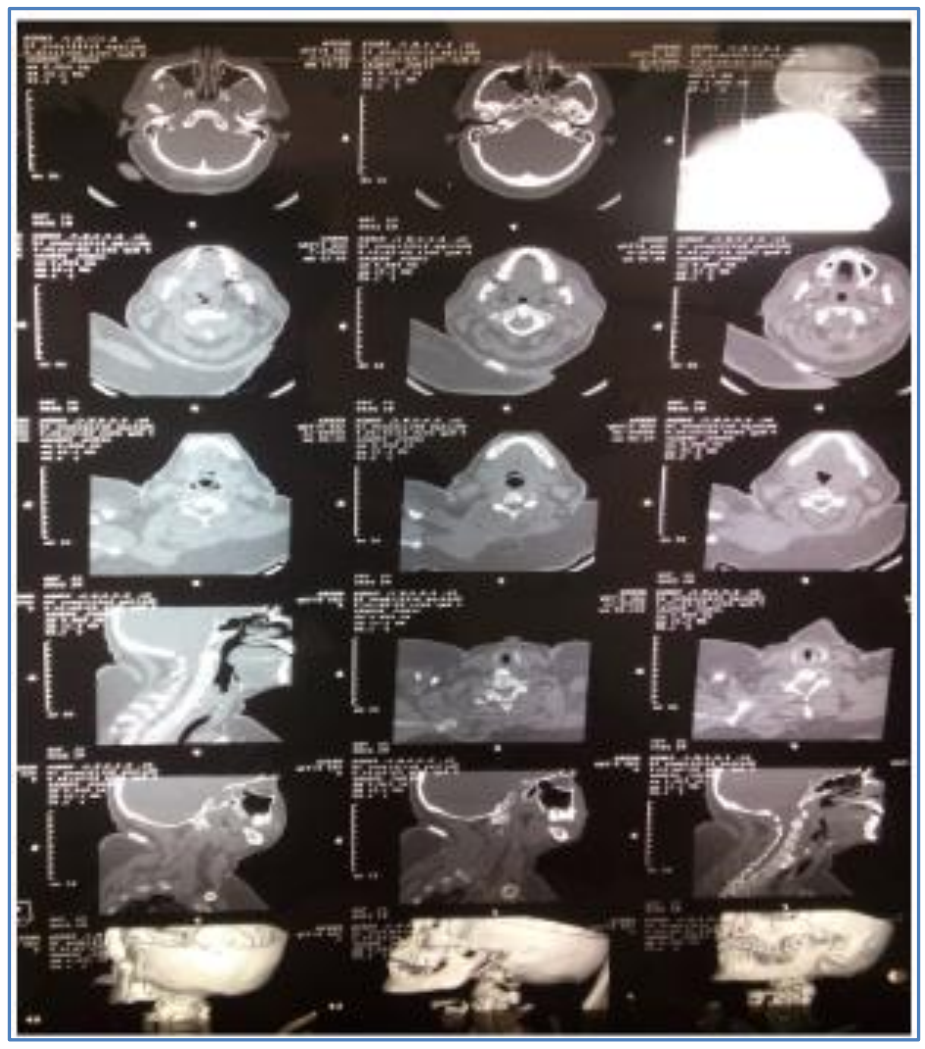

Fig. 1: Showing fracture lateral mass C1 


\section{CASE REPORT}

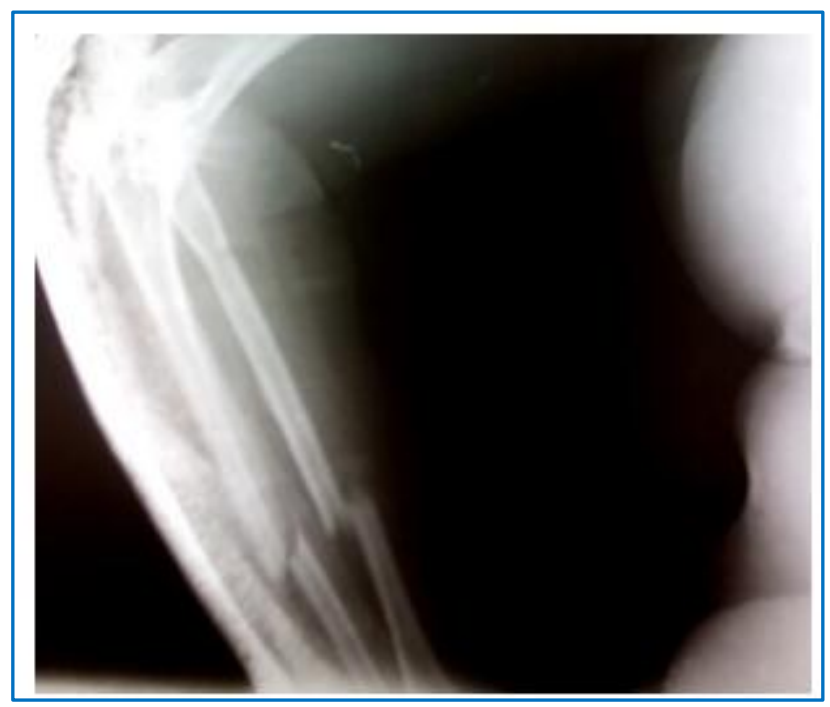

Fig. 2: Showing fracture both bones forearm RT

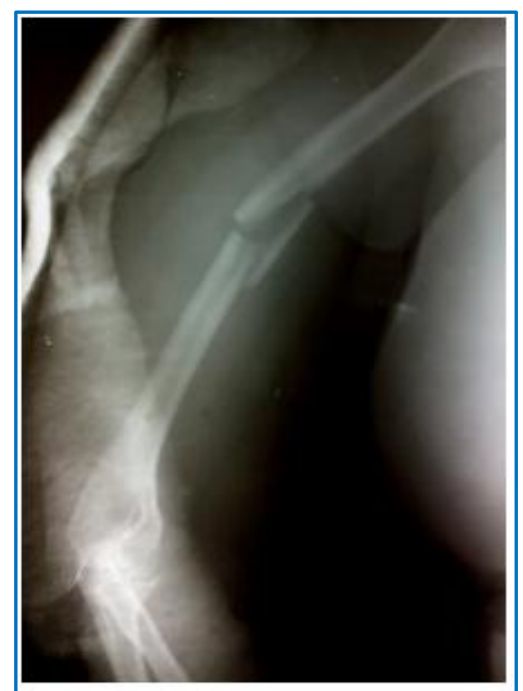

Fig. 3: Showing fracture humerus left

\section{AUTHORS:}

1. Usha Kumari Chaudhary

2. Sudershan Chaudhary

3. Vishal Devra

4. Arvind Kumar

5. Shelly Rana

\section{PARTICULARS OF CONTRIBUTORS:}

1. Senior Resident, Department of Anaesthesia, Dr. RPGMC, Tanda, Kangra, H. P.

2. Professor \& HOD, Department of Anaesthesia, Dr. RPGMC, Tanda, Kangra, H. P.

3. Junior Resident, Department of Anaesthesia, Dr. RPGMC, Tanda, Kangra, H. P.

FINANCIAL OR OTHER

COMPETING INTERESTS: None
4. Junior Resident, Department of Pharmacology, Dr. RPGMC, Tanda, Kangra, H. P.

5. Associate Professor, Department of Anaesthesia, Dr. RPGMC, Tanda, Kangra, H. P.

\section{NAME ADDRESS EMAIL ID OF THE CORRESPONDING AUTHOR:}

Dr. Usha Kumari Chaudhary,

Senior Resident,

Department of Anaesthesia,

Dr. RPGMC, Tanda,

Kangra, H. P, India.

E-mail: chaudhary.ushaarvind@gmail.com

Date of Submission: 09/06/2015.

Date of Peer Review: 10/06/2015.

Date of Acceptance: 23/06/2015.

Date of Publishing: 27/06/2015. 